\title{
Esterco líquido bovino e uréia no crescimento e produção de biomassa do maracujazeiro amarelo
}

\author{
Liquid cattle manure and urea in soil on growth and biomass production of yellow \\ passion fruit plants
}

\author{
Adriana Araujo Diniz ${ }^{2 *}$, Lourival Ferreira Cavalcante ${ }^{3}$, Alex Matheus Rebequi ${ }^{4}$, Járisson Cavalcante Nunes ${ }^{4}$ e \\ Míriam Alice da Silva Brehm ${ }^{4}$
}

\begin{abstract}
Resumo - Objetivou-se avaliar o efeito da aplicação de esterco bovino líquido e uréia no crescimento e na alocação de biomassa nos diferentes órgãos do maracujazeiro amarelo. O experimento foi desenvolvido no período de setembro de 2006 a dezembro de 2007 , no município de Remígio - PB. O delineamento experimental foi o de blocos ao acaso com três repetições e três plantas por parcela, totalizando 180 plantas para observação, usando esquema fatorial 5 x 2, referente ao esterco bovino líquido (ELB) nas proporções em água (A) de 0\% (0ELB + 4A); 25\% (1ELB + 3A); 50\% (2ELB + 2A); 75\% (3ELB + 1A) e 100\% $(4 \mathrm{ELB}+0 \mathrm{~A})$, tomando $4 \mathrm{~L} \mathrm{planta}^{-1}$ da mistura como volume padrão no solo sem e com nitrogênio, fornecido a cada 30 dias após o plantio até o final do experimento. Aos 420 dias após o plantio foi obtido o diâmetro do caule, contado o número de ramos produtivos e as plantas foram divididas em raízes, caules, ramos laterais, ramos produtivos e folhas para avaliação da matéria seca das partes constituintes do maracujazeiro amarelo. Pelos resultados se constatou que a interação esterco líquido bovino $\mathrm{x}$ nitrogênio exerceu efeitos significativos sobre o diâmetro do caule, número de ramos produtivos, biomassa das raízes, do caule, das folhas, dos ramos laterais e dos ramos produtivos, em que os valores na maioria dos casos aumentaram com os percentuais do esterco líquido de bovino, mas com superioridade nos tratamentos com uréia.
\end{abstract}

Palavras-chave - Maracujazeiro. Adubos e fertilizantes orgânicos. Nitrogênio - Fixação.

\begin{abstract}
This study was carried out in order to evaluate the effect of liquid cattle manure and urea on dry matter production in different parts of yellow passion fruit plants. The experiment was conducted during the period of September 2006 to December 2007, in Remígio county Paraiba State, Brazil. The experimental design was randomized blocks with three replications using the factorial squeme 5 x 2 referring to liquid cattle manure (CLM) diluted with water (W) at levels $0 \%(0 \mathrm{CLM}+4 \mathrm{~W}) ; 25 \%$ $(1 \mathrm{CLM}+3 \mathrm{~W}) ; 50 \%(2 \mathrm{CLM}+2 \mathrm{~W}) ; 75 \%(3 \mathrm{CLM}+1 \mathrm{~W})$ and $100 \%(4 \mathrm{CLM}+0 \mathrm{~W})$ taking $4 \mathrm{~L} \mathrm{plant}^{-1}$ as standard volume of each mixture in soil without and with nitrogen applied monthly from 30 days after the planting to the end of the experiment. At 420 days after planting, were obtained the stem diameter and the number of productive branches of the plants; then, the plants were collected, each plant was divided in root, stem, lateral and productive branches and was obtained the dry matter of each part of the plant. The results showed that the interaction liquid cattle manure $\mathrm{x}$ nitrogen exercise significant effect on stem diameter, productive branches and biomass of the root, stem, leaves, lateral and productive branches, but with statistic superiority to plants with cattle liquid manure and urea applied to the soil.
\end{abstract}

Key words - Passion. Manure and fertilizers organic. Nitrogen - Fixation.

\footnotetext{
* Autor para correspondência

${ }^{1}$ Recebido para publicação em 20/08/2009; aprovado em 05/05/2011

Parte da Tese de Doutorado da primeira autora apresentada no PPG em Agronomia/CCA/UFPB

${ }^{2}$ Bolsista PNPD/CAPES/DCAT/UFERSA, Mossoró-RN, Brasil, adrisolos@bol.com.br

${ }^{3}$ Departamento de Solos e Engenharia Rural, Centro de Ciências Agrárias/UFPB, Cidade Universitária, Areia-PB, Brasil, 58.397-000, lofeca@ cca.ufpb.br

${ }^{4}$ Programa de Pós-Graduação em Ciência do Solo/CCA/UFPB, Areia-PB, Brasil, rebequi@yahoo.com.br
} 


\section{Introdução}

O maracujazeiro amarelo (Passiflora edulis Sims f. flavicarpa Deg) é uma frutífera muito cultivada no Brasil, em função do rápido retorno do capital investido pelos produtores em relação a muitas frutíferas como citros, goiaba e graviola (LIMA, 2002). Apesar disso, a produtividade nacional é variada e, na maioria das vezes, baixa, inferior a $15 \mathrm{t} \mathrm{ha}^{-1}$ (IBGE, 2008) em relação ao potencial produtivo da cultura que pode chegar a mais de $40 \mathrm{t} \mathrm{ha}^{-1}$ (SOUSA et al., 2003). Essa cultura apresenta expressiva importância no setor agrícola brasileiro, principalmente devido às qualidades físico-químicas e fármaco-terapêuticas dos frutos, além da alta aceitação pelo mercado consumidor (NATALE et al., 2006; REBELLO et al., 2007).

Atualmente, devido aos altos custos de produção e dos riscos de contaminação do meio ambiente o homem vem repensando e buscando novas alternativas para o sistema produtivo. Uma das possibilidades se fundamenta na agricultura ecológica que prioriza a qualidade dos produtos, reduz os níveis de contaminação do solo, água, planta, do próprio homem e dos componentes vivos dos agroecossistemas (ALVES et al., 2001; RODOLFO JÚNIOR; CAVALCANTE; BURITI, 2008).

Tradicionalmente, o maracujazeiro amarelo tem sido cultivado quase que exclusivamente sob fertilização mineral do solo e pulverização das plantas com agroquímicos. Nas últimas duas décadas o consumidor mundial, inclusive o brasileiro, está sendo mais exigente por alimentos produzidos com menos emprego de fertilizantes sintéticos e agrotóxicos. Nesse sentido, os biofertilizantes, comuns (Esterco fresco de bovino + água) e os biofertilizantes enriquecidos com macro e micronutrientes vêm sendo utilizados na produção de mudas e no crescimento das plantas. Esses insumos foram inicialmente mais empregados por via foliar (BETTIOL; TRATCH; GALVÃO, 1998), mas podem também ser aplicados diretamente no solo (CAVALCANTE et al., 2007; RODRIGUES et al., 2009).

A importância do biofertilizante no crescimento das plantas não se deve aos valores quantitativos dos seus componentes químicos que, em geral, são baixos, mas no aspecto qualitativo, devido sua diversidade química. Estudos recentes indicam que o biofertilizante possui quase todos os macro e micronutrientes essenciais aos vegetais (RODOLFO JÚNIOR; CAVALCANTE; BURITI, 2008). Além da diversidade química, o biofertilizante pode estimular a atividade microbiológica e enzimática do solo, promover a liberação de nutrientes e a melhoria física do solo, resultando em maior crescimento e produção de biomassa das plantas (ARAÚJO et al., 2008; LAGREID; BOCKMAN; KAARSTAD, 1999; PRATES; MEDEIROS, 2001).
Apesar da ação positiva do esterco líquido de bovino ao crescimento, produção e qualidade dos frutos do maracujazeiro amarelo, estudos indicam que o insumo não substitui o fertilizante mineral durante o crescimento inicial e na produção das plantas (RODOLFO JÚNIOR; CAVALCANTE; BURITI, 2008; RODRIGUES et al., 2009). Essa afirmativa se baseia no maior crescimento e produção de maracujazeiro amarelo submetidos a tratamentos com o biofertilizante comum (esterco fresco mais água) e supermagro (esterco fresco mais água mais macro e micronutrientes) adicionados com fertilizantes minerais em relação aos que continham apenas os insumos orgânicos (RODOLFO JÚNIOR; CAVALCANTE; BURITI, 2008; RODRIGUES et al., 2009). O crescimento e produção inferiores nos tratamentos com o insumo orgânico e mineral deve resultar também na perda da capacidade de produção e alocação de biomassa pelas plantas em geral, inclusive pelo maracujazeiro amarelo.

Pelo exposto objetivou-se avaliar os efeitos da aplicação do esterco líquido bovino e da uréia no crescimento e na produção de biomassa do maracujazeiro amarelo.

\section{Material e métodos}

O trabalho foi desenvolvido no período de setembro de 2006 a dezembro de 2007, na propriedade Sítio Macaquinhos, situada no município de Remígio, $\mathrm{PB}$, microrregião de Esperança, $\mathrm{PB}$, que se situa a 6 53 '00' de latitude Sul, 36 02 '00' de longitude a Oeste do meridiano de Greenwich e a altitude de $470 \mathrm{~m}$. O clima do município é do tipo As' quente e úmido, com temperatura média de $24{ }^{\circ} \mathrm{C}$, e umidade relativa do ar que varia entre 70 e $80 \%$, com pluviosidade média anual nos últimos três anos inferior a $900 \mathrm{~mm}$, concentrada no intervalo de março a junho.

O solo da área experimental foi classificado como Cambissolo Húmico Distrófico (EMBRAPA, 2006), profundo, bem drenado, de textura franco-arenosa e, portanto, adequado ao cultivo do maracujazeiro amarelo. Amostras de solo foram coletadas nas camadas de 0-20 e de 21-40 cm para a caracterização química e física (TAB. 1), usando as metodologias sugeridas pela Embrapa (1997).

O delineamento experimental foi o de blocos ao acaso com três repetições usando o esquema fatorial $5 \times 2$. Os tratamentos consistiram de cinco doses de esterco bovino aplicado ao solo, na presença e ausência de adubações com uréia. $\mathrm{O}$ esterco líquido bovino (ELB) foi diluído em água $(\mathrm{A})$ e aplicado numa área de $0,8 \mathrm{~m}^{2}$ nas seguintes proporções: 0\% (0 ELB + 4A); 25\% (1ELB + 3A); 50\% $(2 \mathrm{ELB}+2 \mathrm{~A}) ; 75 \%(3 \mathrm{ELB}+1 \mathrm{~A})$ e $100 \%(4 \mathrm{ELB}+0 \mathrm{~A})$ 
adotando-se padrão $4 \mathrm{~L}_{\text {planta }}{ }^{-1}$ aplicado uma semana antes e a cada 90 dias após o plantio até o final do experimento. A uréia foi aplicada mensalmente na dose necessária para fornecer $10 \mathrm{~g}_{\text {planta }}{ }^{-1}$ de $\mathrm{N}$ aos 30 e 60 dias após o plantio e após essa idade $20 \mathrm{~g} \mathrm{planta}^{-1}$ até o final da colheita.

O esterco líquido bovino foi obtido através de fermentação anaeróbia adicionando partes iguais de esterco fresco de bovino e água não salina e não clorada, em um recipiente de polietileno e mantida hermeticamente fechada durante trinta dias. Durante o período de preparação e a cada 24 horas foi feita a homogeneização para melhor eficiência da fermentação. Para liberação dos gases produzidos durante a fermentação, conectou-se na parte superior do biodigestor uma mangueira fina e a outra extremidade foi submersa em um recipiente com água para evitar a entrada de ar. O esterco foi aplicado na forma líquida, por isso foi analisado como água para irrigação, conforme indicado na Tabela 2.

O transplantio foi realizado em setembro de 2006 utilizando-se mudas de maracujazeiro amarelo obtidas de sementes de frutos selecionados por seleção massal, em covas abertas nas dimensões $0,40 \times 0,40 \times 0,40 \mathrm{~m}$ no espaçamento de $2,5 \times 40 \mathrm{~m}$, preenchidas com material de solos dos primeiros $20 \mathrm{~cm}$ superficiais. Para sustentação das plantas utilizou-se espaldeira com um arame liso $\mathrm{n}^{\mathrm{o}} 12$ instalado no topo das estacas. A irrigação foi efetuada no período de setembro de 2006 a agosto de 2007 pelo método de aplicação localizada por gotejamento, usando dois emissores, do tipo catife por planta, com vazão de $3,75 \mathrm{~L} \mathrm{~h}^{-1}$, fornecendo a cada planta diariamente nos primeiros 90 dias $4 \mathrm{~L}$ de água, a partir dessa idade $8 \mathrm{~L} \mathrm{planta}^{-1}$ dia $^{-1}$ até a floração e a partir da floração $12 \mathrm{~L}_{\text {planta }}{ }^{-1}$ dia $^{-1}$.

No final do ciclo produtivo da cultura, aos 420 dias após o plantio, foi obtido o diâmetro do caule das plantas, a $10 \mathrm{~cm}$ do colo, usando um paquímetro de precisão 1:50 e contados os ramos produtivos representados pelos ramos secundários, terciários e quaternários. Em seguida, as plantas foram coletadas e separadas as raízes, caules, ramos laterais, ramos produtivos e folhas; após a lavagem com água, foram postas a secarem em estufa com circulação de ar até massa constante. Em seguida, foram obtidos os valores da matéria seca dos respectivos órgãos das plantas de maracujazeiro amarelo, conforme metodologia adotada por Benincasa (2003).

Tabela 1 - Caracterização química e física do solo às camadas de 0-20 e 21-40 cm

\begin{tabular}{|c|c|c|c|c|c|}
\hline \multirow{2}{*}{ Atributos químicos } & \multicolumn{2}{|c|}{ Camadas } & \multirow{2}{*}{ Atributos físicos } & \multicolumn{2}{|c|}{ Camadas } \\
\hline & $0-20$ & $21-40$ & & $0-20$ & $21-40$ \\
\hline $\mathrm{pH}(1: 2,5)$ & 5,55 & 4,95 & AMG $\left(\mathrm{g} \mathrm{kg}^{-1}\right)$ & 111 & 100 \\
\hline $\mathrm{P}\left(\mathrm{mg} \mathrm{dm}^{-3}\right)$ & 9,83 & 8,92 & $\mathrm{AG}\left(\mathrm{g} \mathrm{kg}^{-1}\right)$ & 129 & 120 \\
\hline $\mathrm{K}\left(\mathrm{mg} \mathrm{dm}^{-3}\right)$ & 57,25 & 44,00 & $\mathrm{AM}\left(\mathrm{g} \mathrm{kg}^{-1}\right)$ & 235 & 217 \\
\hline $\mathrm{Na}\left(\mathrm{cmol}_{\mathrm{c}} \mathrm{dm}^{-3}\right)$ & 0,01 & 0,03 & $\mathrm{AF}\left(\mathrm{g} \mathrm{kg}^{-1}\right)$ & 266 & 275 \\
\hline $\mathrm{Ca}^{2+}+\mathrm{Mg}^{2+}\left(\mathrm{cmol}_{\mathrm{c}} \mathrm{dm}^{-3}\right)$ & 1,82 & 1,42 & $\operatorname{AMF}\left(\mathrm{g} \mathrm{kg}^{-1}\right)$ & 68 & 82 \\
\hline $\mathrm{Ca}^{2+}\left(\mathrm{cmol}_{\mathrm{c}} \mathrm{dm}^{-3}\right)$ & 1,47 & 1,20 & Silte $\left(\mathrm{g} \mathrm{kg}^{-1}\right)$ & 86 & 91 \\
\hline $\mathrm{Mg}^{2+}\left(\mathrm{cmol}_{\mathrm{c}} \mathrm{dm}^{-3}\right)$ & 0,35 & 0,22 & Argila $\left(\mathrm{g} \mathrm{kg}^{-1}\right)$ & 105 & 115 \\
\hline $\mathrm{Al}^{3+}\left(\mathrm{cmol}_{\mathrm{c}} \mathrm{dm}^{-3}\right)$ & 0,05 & 0,20 & $\operatorname{ADA}\left(\mathrm{g} \mathrm{kg}^{-1}\right)$ & 31,5 & 56,5 \\
\hline $\mathrm{H}+\mathrm{Al}\left(\mathrm{cmol}_{\mathrm{c}} \mathrm{dm}^{-3}\right)$ & 2,35 & 2,60 & GF $(\%)$ & 703 & 512 \\
\hline Carbono $\left(\mathrm{g} \mathrm{kg}^{-1}\right)$ & 5,56 & 4,39 & $\operatorname{DS}\left(\mathrm{g} \mathrm{dm}^{-3}\right)$ & 1,60 & 1,56 \\
\hline M. O. $\left(\mathrm{g} \mathrm{kg}^{-1}\right)$ & 9,59 & 7,57 & $\mathrm{DP}\left(\mathrm{g} \mathrm{dm}^{-3}\right)$ & 2,65 & 2,65 \\
\hline Cobre $\left(\mathrm{mg} \mathrm{dm}^{-3}\right)$ & 0,32 & 0,70 & PT $\left(\mathrm{m}^{3} \mathrm{~m}^{-3}\right)$ & 0,4 & 0,4 \\
\hline Ferro $\left(\mathrm{mg} \mathrm{dm}^{-3}\right)$ & 19,60 & 41,07 & $\mathrm{CC}\left(\mathrm{g} \mathrm{kg}^{-1}\right)$ & 98 & 94 \\
\hline Zinco $\left(\mathrm{mg} \mathrm{dm}^{-3}\right)$ & 0,14 & 0,21 & $\mathrm{PM}\left(\mathrm{g} \mathrm{kg}^{-1}\right)$ & 28 & 29 \\
\hline Manganês (mg dm ${ }^{-3}$ ) & 2,64 & 2,40 & $\mathrm{AD}\left(\mathrm{g} \mathrm{kg}^{-1}\right)$ & 70 & 65 \\
\hline Boro $\left(\mathrm{mg} \mathrm{dm}^{-3}\right)$ & 0,82 & 0,80 & $\mathrm{CT}$ & FA & FA \\
\hline
\end{tabular}

$\mathrm{AMG}=$ areia muito grossa $(2,00-1,00 \mathrm{~mm}) ; \mathrm{AG}=$ areia grossa $(1,00-0,50 \mathrm{~mm}) ; \mathrm{AM}=$ areia média $(0,50-0,25 \mathrm{~mm}) ; \mathrm{AF}=\operatorname{areia}$ fina $(0,25$ - 0,106 mm); AMF = areia muito fina $(0,106-0,053 \mathrm{~mm})$; Silte $(0,053-0,002 \mathrm{~mm})$; Argila $(<0,02 \mathrm{~mm}) ; \mathrm{ADA}=$ argila dispersa em água; GF = grau de floculação; $\mathrm{DS}=$ densidade do solo; $\mathrm{DP}=$ densidade de partículas; $\mathrm{PT}=$ porosidade total; $\mathrm{CC}=$ capacidade de campo; $\mathrm{PM}=$ ponto de murcha; $\mathrm{AD}=$ água disponível; $\mathrm{CT}=$ classificação textural: $\mathrm{FA}=$ franco arenosa 
Tabela 2 - Composição química do esterco líquido nas proporções correspondentes aos tratamentos aplicados ao solo

\begin{tabular}{cccccc}
\hline \multirow{2}{*}{ Componentes } & \multicolumn{5}{c}{ Esterco líquido bovino (\%) } \\
\cline { 2 - 5 } & 0 & 25 & 50 & 75 & 100 \\
\hline $\mathrm{pH}$ & 6,16 & 6,34 & 6,39 & 6,49 & 6,74 \\
$\mathrm{Ca}^{2+}\left(\mathrm{mmol}^{\mathrm{c}} \mathrm{L}^{-1}\right)$ & 1,15 & 4,26 & 6,51 & 9,77 & 12,51 \\
$\mathrm{Mg}^{2+}\left(\mathrm{mmol}_{\mathrm{c}} \mathrm{L}^{-1}\right)$ & 0,48 & 5,41 & 8,27 & 12,41 & 15,88 \\
$\mathrm{Na}^{+}\left(\mathrm{mmol}_{\mathrm{c}} \mathrm{L}^{-1}\right)$ & 0,74 & 2,54 & 3,89 & 5,48 & 7,92 \\
$\mathrm{~K}^{+}\left(\mathrm{mmol}_{\mathrm{c}} \mathrm{L}^{-1}\right)$ & 0,16 & 6,46 & 9,88 & 14,82 & 19,67 \\
$\mathrm{CO}_{3}^{2-}\left(\mathrm{mmol}_{\mathrm{c}} \mathrm{L}^{-1}\right)$ & Ausente & Ausente & Ausente & Ausente & Ausente \\
$\mathrm{HCO}_{3}^{-}\left(\mathrm{mmol}_{\mathrm{c}} \mathrm{L}^{-1}\right)$ & 0,44 & 2,84 & 4,34 & 6,56 & 8,29 \\
$\mathrm{Cl}^{-}\left(\mathrm{mmol}_{\mathrm{c}} \mathrm{L}^{-1}\right)$ & 1,82 & 13,42 & 20,53 & 30,78 & 39,78 \\
$\mathrm{SO}_{4}^{2-}\left(\mathrm{mmol}_{\mathrm{c}} \mathrm{L}^{-1}\right)$ & 0,22 & 2,81 & 3,30 & 6,45 & 8,13 \\
$\mathrm{CE}^{2}\left(\mathrm{mS} \mathrm{cm}^{-1}\right)$ & 0,25 & 1,89 & 2,90 & 4,35 & 5,54 \\
$\mathrm{RAS}^{2}\left(\mathrm{mmol} \mathrm{L}^{-1}\right)^{1 / 2}$ & 0,82 & 1,16 & 1,43 & 1,64 & 2,11 \\
$\mathrm{Classificação}^{2}$ & $\mathrm{C}_{1} \mathrm{~S}_{1}$ & $\mathrm{C}_{3} \mathrm{~S}_{1}$ & $\mathrm{C}_{3} \mathrm{~S}_{1}$ & $\mathrm{C}_{4} \mathrm{~S}_{1}$ & $\mathrm{C}_{4} \mathrm{~S}_{1}$ \\
\hline
\end{tabular}

$0 \%=$ água de irrigação; $25 \%=1$ bio +3 água; $50 \%=2$ bio +2 água; $75 \%=3$ bio +1 água; $100 \%=$ biofertilizante; $\operatorname{RAS}=\mathrm{Na}^{+}\left[\left(\mathrm{Ca}^{2+}+\mathrm{Mg}^{2+}\right) / 2\right]^{1 / 2}$; $\mathrm{C}_{1}, \mathrm{C}_{3}$ e $\mathrm{C}_{4}=$ Risco baixo, alto e muito alto da água salinizar o solo, em relação à água de irrigação; $\mathrm{S} 1$ = Risco baixo de sodificação do solo em relação a água de irrigação

Os dados foram submetidos à análise de variância, as médias referentes ao tratamento com uréia foram comparadas pelo teste de Tukey ao nível 5\% de significância e as do esterco bovino líquido por regressão polinomial (FERREIRA, 2000).

\section{Resultados e discussão}

A interação esterco líquido bovino x uréia exerceu efeitos significativos sobre o diâmetro do caule, número de ramos produtivos e na produção de biomassa dos distintos órgãos das plantas (TAB. 3). Qualitativamente o comportamento das variáveis está de acordo com os obtidos por Araujo et al. (2008) que constataram que o crescimento do maracujazeiro amarelo foi estimulado pelas doses de biofertilizante bovino. Entretanto, quantitativamente foram registradas variações de tendências para uma mesma variável em função das doses de esterco líquido fermentado de bovino no solo sem e com uréia. Das variáveis avaliadas, a produção de biomassa pelos ramos produtivos apresentou o maior coeficiente de variação $(38,25 \%)$ devido à eliminação de ramos sem finalidade agrícola retirados com a poda de limpeza, uma vez que a avaliação se referiu apenas ao final do ciclo produtivo da cultura.

As doses de esterco líquido bovino aplicadas a cada 90 dias e da uréia adicionada mensalmente no solo estimularam o crescimento das plantas pelo diâmetro caulinar até os 420 dias após o transplantio (FIG. 1). Observa-se na referida figura que o diâmetro caulinar das plantas no solo com esterco líquido sem adição de uréia aumentou até o valor de $21,78 \mathrm{~mm}$ na dose estimada de $70,55 \%$ do esterco líquido fornecido.

Nos tratamentos com esterco líquido e uréia no solo, os valores de diâmetro caulinar foram superiores em relação ao solo sem aplicação de N (FIG. 1). Os dados aumentaram até o maior valor de $23,36 \mathrm{~mm}$ correspondente à dose máxima estimada de 56,6\% do insumo. Provavelmente esse aumento seja em função da uréia que exerceu ação positiva no crescimento das plantas por estimular a formação de gemas floríferas e frutíferas, com reflexos também no maior crescimento vegetativo, como comentado por Santos et al. (2006) ao avaliarem a influência do nitrogênio na cultura do maracujazeiro amarelo. Por outro lado, observa-se que os ganhos em diâmetro caulinar se equipararam entre os tratamentos sem e com uréia na dose de $86,26 \%$ de esterco líquido bovino; a partir dessa dose houve uma redução dos valores nas plantas dos tratamentos com aplicação de uréia. Essa redução expressa a necessidade de maior diluição do esterco líquido bovino ao ser aplicado ao solo juntamente com a uréia. Concentrações do insumo orgânico acima desse valor associadas ao nitrogênio devem ter exercido ação tóxica por aumento da concentração de $\mathrm{N}$ e do total de cátions solúveis no ambiente radicular acima do tolerado pela cultura, resultando na inibição do crescimento pelo 
diâmetro das plantas. Situação semelhante foi registrada por Santos (2004) ao monitorar o crescimento inicial do maracujazeiro amarelo no solo com esterco líquido de bovino fornecido a cada 60 dias após o plantio.

O número de ramos produtivos respondeu significativamente aos efeitos da interação esterco líquido bovino x uréia ao nível de $1 \%$ de significância (TAB. 3). Na ausência de uréia, o número de ramos produtivos (secundário, terciário e quaternário) variou de 34,9 a 53,3 ramos planta-1 (FIG. 2); nos tratamentos com esterco líquido e com uréia os valores aumentaram até o maior valor de 58,43 ramos planta ${ }^{-1}$ na dose estimada de $29,75 \%$ de esterco líquido. Pelos resultados, aos 420 dias após o plantio, quando ocorreu a estabilização da emissão dos ramos, constatou-se inibição da emissão dos ramos produtivos com o aumento dos níveis de esterco líquido bovino, porém, mesmo com essa redução, os dados superaram os tratamentos sem aplicação de uréia até a dose de $97,7 \%$.

Asuperioridadedosramos produtivosnostratamentos com uréia em relação ao solo sem uréia evidencia, como constatado para o diâmetro do caule, que o esterco líquido bovino isolado não supre as exigências nutricionais do maracujazeiro amarelo. O maior número de ramos nos tratamentos com uréia expressa a função estimuladora do nutriente e deste associado ao esterco líquido no crescimento vegetativo e produtivo do maracujazeiro amarelo, uma vez que o aumento da produção depende do aumento dos ramos produtivos (CAVALCANTE et al., 2003; RODOLFO JÚNIOR; CAVALCANTE; BURITI, 2008). Resultados

Tabela 3 - Análises de variância, referentes aos valores de quadrado médio das variáveis diâmetro do caule (DC), número de ramos produtivos (NRP), biomassa da raiz (BR), biomassa do caule (BC), biomassa das folhas (BF), biomassa dos ramos laterais (BRL) e biomassa dos ramos produtivos (BRP) do maracujazeiro amarelo, em função da aplicação de esterco líquido bovino (ELB) e uréia (U) no solo

\begin{tabular}{ccccccccc}
\hline \multirow{2}{*}{ FV } & \multirow{2}{*}{ GL } & \multicolumn{7}{c}{ Quadrados Médios } \\
\cline { 3 - 8 } & & DC & NRP & BR & BC & BF & BRL & BRP \\
\hline Bloco & 2 & $10,65^{*}$ & $3,27^{\text {ns }}$ & $6,93^{\text {ns }}$ & $10,65^{*}$ & $1075,49^{\text {ns }}$ & $56,91^{\text {ns }}$ & $3,27^{\text {ns }}$ \\
ELB (A) & 4 & $4777,29^{* *}$ & $174,39^{* *}$ & $3757,73^{* *}$ & $5,68^{* *}$ & $48063,39^{* *}$ & $540,39^{*}$ & $174,39^{*}$ \\
U (B) & 1 & $4814,60^{*}$ & $1373,77^{* *}$ & $986,48^{* *}$ & $5,72^{*}$ & $38389,799^{\text {ns }}$ & $508,24^{\text {ns }}$ & $1373,76^{\text {ns }}$ \\
A x B & 4 & $6018,92^{* *}$ & $269,88^{* *}$ & $1180,04^{* *}$ & $7,15^{* *}$ & $75930,109^{* *}$ & $7230,49^{* *}$ & $269,88^{* *}$ \\
Resíduo & 18 & 841,18 & 11,27 & 107,92 & 841,18 & 9506,509 & 141,82 & 11,26 \\
CV (\%) & & 18,64 & 6,79 & 18,46 & 18,64 & 35,59 & 14,83 & 38,25 \\
\hline
\end{tabular}

$\mathrm{FV}=$ fonte de variação; $\mathrm{GL}=$ graus de liberdade; $\mathrm{ns}=$ não significativo ${ }^{*} \mathrm{e} * *$ respectivamente significativos para $\mathrm{p}<0,05 \mathrm{e} \mathrm{p}<0,01 ; \mathrm{CV}=\mathrm{Coeficiente}$ de variação

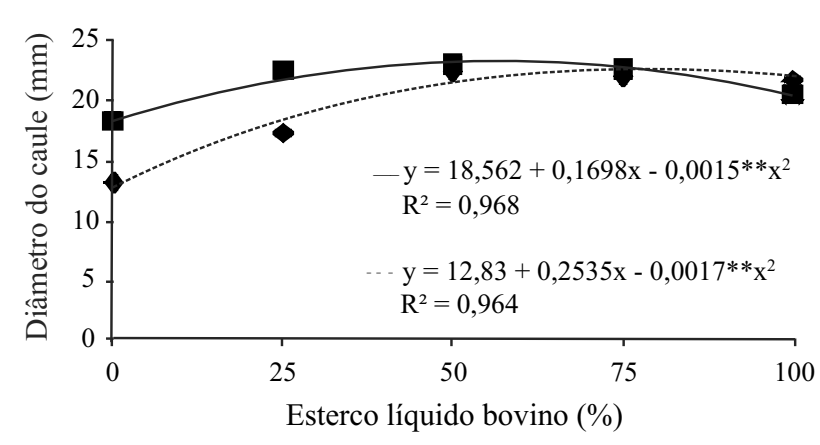

Figura 1 - Valores de diâmetro caulinar do maracujazeiro amarelo em resposta à aplicação no solo de esterco líquido bovino, sem (- - ) e com (-) uréia

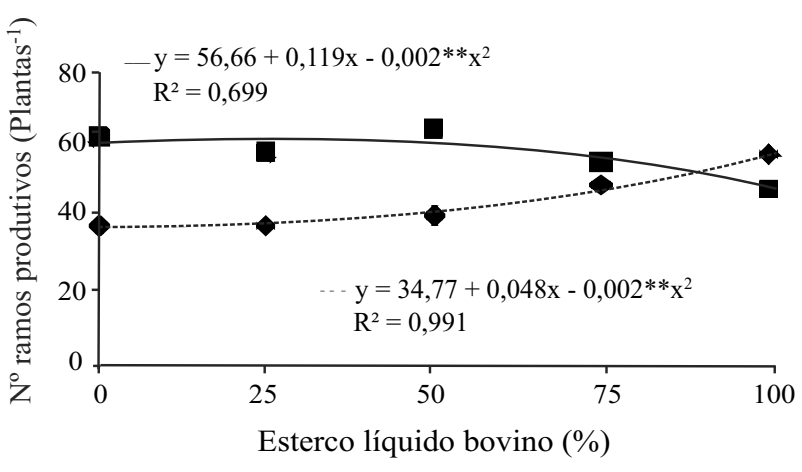

Figura 2 - Número de ramos produtivos do maracujazeiro amarelo em resposta à aplicação no solo de esterco líquido bovino, sem (- -) e com (-) uréia 
semelhantes foram evidenciados por Araújo et al. (2008) ao constatarem aumento no número de ramos produtivos do maracujazeiro amarelo com aplicação de biofertilizante comum.

Pelos resultados obtidos após a colheita, verificase que a interação esterco líquido bovino $\mathrm{x}$ uréia exerceu efeito significativo sobre a produção de biomassa do caule (TAB. 3). Nos tratamentos com esterco líquido sem uréia, a biomassa caulinar aumentou em função das concentrações do insumo orgânico aplicado (FIG. 3). Os valores cresceram até o maior valor de 200,85 g na dose ótima de $91 \%$ de esterco líquido bovino. No solo com uréia os dados se ajustaram ao modelo de regressão quadrático com valores variando de 147,02 a 209,91 g de biomassa caulinar em função dos níveis de esterco líquido aplicados no solo. Esse aumento em biomassa caulinar em função dos níveis de esterco líquido aplicado caracteriza o efeito positivo da uréia e do esterco líquido como ativadores do crescimento das plantas. $\mathrm{Na}$ dose de 38,9\% de esterco líquido as plantas produziram o mesmo valor de biomassa caulinar nos tratamentos sem e com adição de uréia. A partir dessa dose, houve maior ganho em biomassa na ausência de uréia, possivelmente devido a uma ação inibidora do crescimento pela ação conjunta da salinidade crescente das doses do esterco líquido (TAB. 2) e da uréia. Essa situação diminui o potencial osmótico da solução do solo (MUNSS; TESTER, 2008). Os resultados obtidos não superaram os 119,98 g planta $^{-1}$ de biomassa do caule apresentados por Araujo et al. (2000), ao avaliarem o efeito do volume de água e da cobertura morta sobre o crescimento inicial do maracujazeiro amarelo.

A biomassa foliar (FIG. 4) cresceu com o aumento das concentrações de esterco líquido no solo sem uréia até a dose máxima estimada de $56,18 \%$ correspondente a $314,78 \mathrm{~g} \mathrm{planta}^{-1}$. O fornecimento de doses superiores do insumo provocou declínio na produção de biomassa das folhas. Nos tratamentos com uréia, o aumento nas doses de esterco líquido de bovino proporcionou um ganho em biomassa de 206,53 para 452,06 g. A adição mensal de uréia ao maracujazeiro favoreceu a ação estimuladora desse macronutriente ao crescimento das plantas. Essa situação está em conformidade com Epstein e Bloom (2006) que relataram que as adubações nitrogenadas são importantes, porque, não só interferem no crescimento, mas também no rendimento e na qualidade do produto colhido. Os resultados foram superiores aos apresentados por Cavalcante et al. (2008), que obtiveram valores médios abaixo de $50 \mathrm{~g} \mathrm{planta}^{-1}$ para a alocação de biomassa foliar após o término da colheita do maracujazeiro amarelo e por Araujo et al. (2000), que registraram valor médio de 84,61 g planta $^{-1}$ de biomassa foliar.

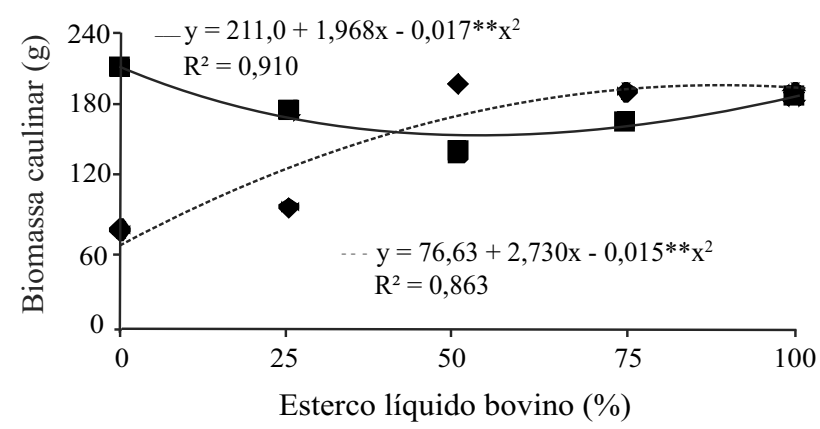

Figura 3 - Valores de biomassa caulinar do maracujazeiro amarelo em resposta à aplicação no solo de esterco líquido bovino, sem (- - ) e com (-) uréia

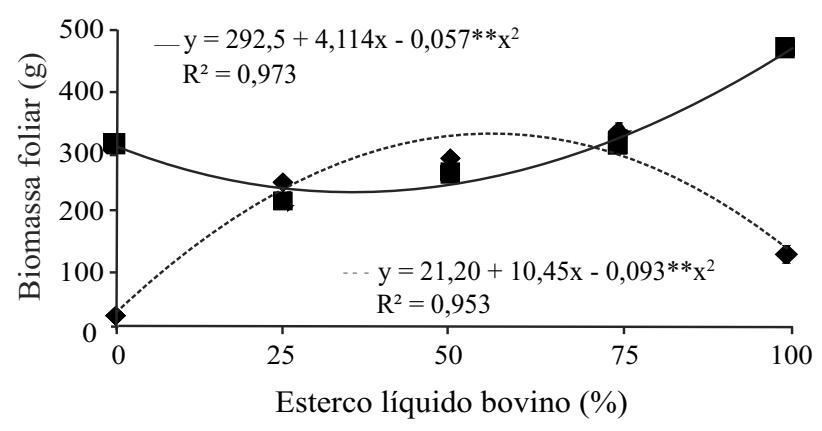

Figura 4 - Valores de biomassa foliar do maracujazeiro amarelo em resposta à aplicação no solo de esterco líquido bovino, sem (- - -) e com (-) uréia

O aumento das doses de esterco líquido bovino influenciou significativamente a produção de biomassa pelas raízes (FIG. 5). Na presença de uréia no solo, essa variável foi elevada de 32,59 para 72,73 e no solo sem uréia de 29,11 para 112,49 g, refletindo-se em crescimento de biomassa seca do maracujazeiro amarelo. Percebe-se que a biomassa radicular foi superior no solo com uréia até a dose de $71,2 \%$ e a partir daí os valores sem aplicação de uréia superaram aos dos tratamentos com o insumo mineral. Observa-se também que a dose de 71,2\% de esterco líquido bovino foi necessária para que a planta produzisse a mesma proporção de biomassa radicular, independentemente da adição ou não de uréia ao solo. Como constatado para o diâmetro do caule, número de ramos produtivos e a biomassa caulinar, essa redução na produção de biomassa radicular referente aos níveis mais elevados de esterco líquido bovino no solo com uréia, expressa a importância da diluição do insumo orgânico ao ser aplicado ao solo. Concentrações altas do insumo orgânico possivelmente inibam o crescimento radicular, como constatado por 
Santos (2004) ao aplicar $3 \mathrm{~L}_{\text {planta }}{ }^{-1}$ de biofertilizante bovino, a cada 60 dias após o transplantio na cultura do maracujazeiro. Apesar da adição dos insumos orgânicos ao solo contribuírem para a melhoria física (MELLEK et al., 2010), química (BUDZIAK; MAIA; MANGRICH, 2004) e biológica (ASERI et al., 2008) doses excessivas podem comprometer o comportamento vegetativo das plantas, inclusive do maracujazeiro amarelo.

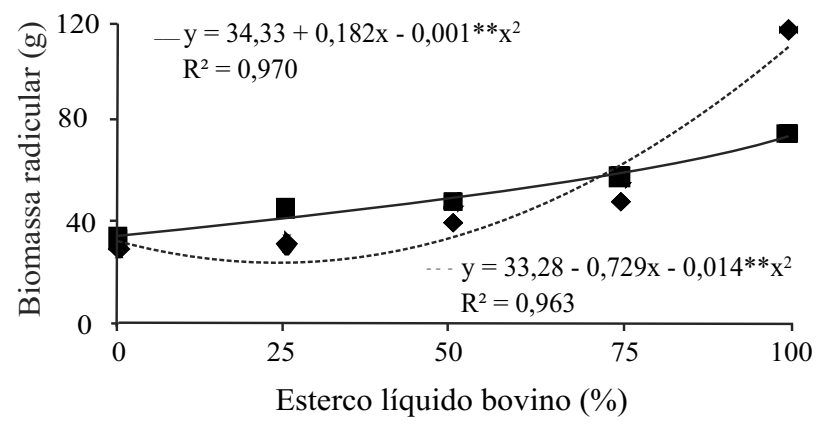

Figura 5 - Valores de biomassa radicular do maracujazeiro amarelo em resposta à aplicação no solo de esterco líquido bovino, sem (- - ) e com (-) uréia

A biomassa de ramos laterais sofreu interferência da interação esterco líquido bovino $\mathrm{x}$ uréia ao nível de $1 \%$ de probabilidade. No solo sem uréia a biomassa dos ramos laterais aumentou até o valor de 133,01 $\mathrm{g} \mathrm{planta}^{-1}$ na dose ótima estimada de $72,85 \%$ do esterco líquido de bovino (FIG. 6). Por outro lado, nos tratamentos com nitrogênio, a biomassa dos ramos laterais das plantas decresceu com o aumento do respectivo insumo orgânico de 129,12 para 48,69 g planta $^{-1}$. O comportamento dos dados está em consonância com Souza et al. (2007) que constataram que a aplicação de doses elevadas de nitrogênio na forma de uréia inibiu a produção de matéria seca em mudas de maracujazeiro doce.

A interação esterco líquido bovino x uréia exerceu efeitos significativos ao nível de $1 \%$ de probabilidade na biomassa dos ramos produtivos das plantas, com superioridade na maioria das doses do insumo orgânico associado com nitrogênio (FIG. 7). No solo sem uréia a biomassa dos ramos das plantas aumentou até 385,52 g referente à dose máxima estimada de $96,96 \%$ do esterco líquido fornecido enquanto no solo com uréia aumentou de 295,2 a 456,77 $\mathrm{g} \mathrm{planta}^{-1}$. Como observado, para o diâmetro do caule, número de ramos produtivos, biomassa caulinar, foliar e radicular verifica-se a necessidade de adição de uréia ao insumo orgânico para melhor expressão do crescimento do maracujazeiro amarelo.

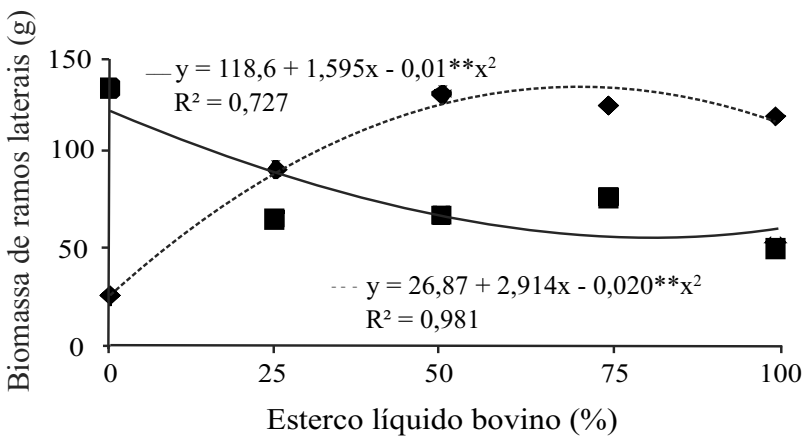

Figura 6 - Valores de ramos laterais do maracujazeiro amarelo em resposta à aplicação no solo de esterco líquido bovino, sem (- - ) e com (-) uréia

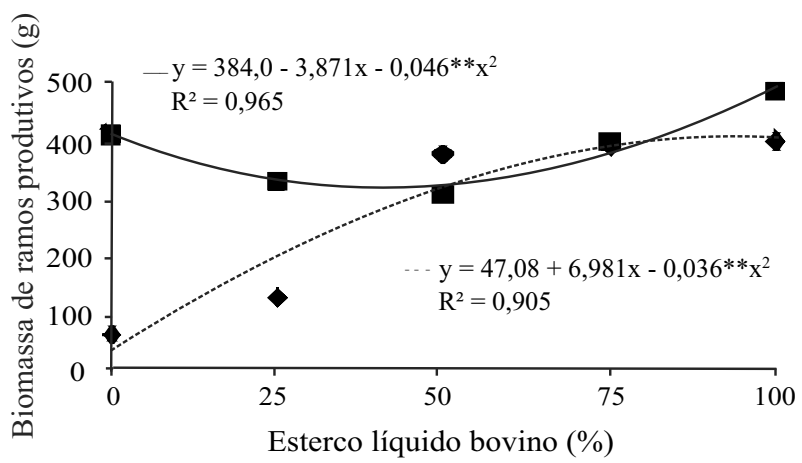

Figura 7 - Valores de biomassa de ramos produtivos do maracujazeiro amarelo em resposta à aplicação no solo de esterco líquido bovino, sem (- - -) e com (-) uréia

\section{Conclusões}

1. O maior crescimento do diâmetro caulinar e número de ramos produtivos ocorreram nas plantas dos tratamentos com esterco líquido bovino e uréia;

2. O esterco líquido fermentado de bovino estimulou o crescimento e a produção de biomassa nos distintos órgãos das plantas, mas não substitui o nitrogênio aplicado na forma de fertilizante mineral.

\section{Agradecimentos}

Os autores agradecem ao $\mathrm{CNPq}$ pelo suporte financeiro e à CAPES pela concessão da bolsa de doutorado do primeiro autor. 


\section{Referências}

ALVES, S. B. et al. Trofobiose e microrganismos na proteção de plantas: biofertilizantes e entomopatógenos na citricultura orgânica. Biotecnologia, Ciência e Desenvolvimento, v. 21, n. 01, p. 16-21, 2001.

ARAÚJO, D. C. et al. Efeito do volume de água e da cobertura morta sobre o crescimento inicial do maracujazeiro amarelo. Revista Brasileira de Engenharia Agrícola e Ambiental, v. 04, n. 01, p. 121-124, 2000.

ARAÚJO, L. A. et al. Comportamento do maracujazeiroamarelo (Passiflora edulis $f$. Sims flavicarpa Deg.) sob diferentes dosagens de biofertilizante e intervalos de aplicação. Revista Verde de Agroecologia e Desenvolvimento sustentável, v. 03, n. 04, p. 98-109, 2008.

ASERI, G. K. et al. Biofertilizers improve plant growth, fruit yield, nutrition, metabolism and rhizosphere enzyme activities of Pomegranate (Punica granatum L.) in Indiam Thar Desert. Scientia Horticulturae, v. 117, n. 01, p. 130-135, 2008.

BENINCASA, M. M. Análise de crescimento de plantas. FUNEP, Jaboticabal - SP. 2003. 42p.

BETTIOL, W.; TRATCH, R.; GALVÃO, J. A. H. Controle de doenças de plantas com biofertilizantes. Jaguariúna: EMBRAPA-CNPMA, 1998. 22 p. (EMBRAPA-CNPMA. Circular Técnica, 02).

BUDZIAK, C. R.; MAIA, C. M. B. F.; MANGRICH, A. S. Transformações químicas da matéria orgânica durante a compostagem de resíduos da indústria madeireira. Química Nova, v. 27, n. 03, p. 399-403, 2004.

CAVALCANTE, L. F. et al. Biomassa do maracujazeiro-amarelo em solo irrigado com água salina protegido contra as perdas hídricas. Revista Verde de Agroecologia e Desenvolvimento Sustentável, v. 03, n. 03, p. 26-34, 2008.

CAVALCANTE, L. F. et al. Caracterização qualitativa de frutos de maracujá-amarelo (Passiflora edulis f. flavicarpa Deg.) em função da salinidade da água de irrigação. Agropecuária Técnica, v. 24, n. 01, p. 39 - 45. 2003.

CAVAlCANTE, L. F. et al. Crescimento e produção do maracujazeiro amarelo em solo de baixa fertilidade tratado com biofertilizantes líquidos. Revista Brasileira de Ciências Agrárias, v. 02, n. 01, p. 15-19, 2007.

EMPRESABRASILEIRADEPESQUISAAGROPECUÁRIA (EMBRAPA). Centro Nacional de Pesquisa de Solos. Manual de métodos de análise de solo. 2. ed. rev. atual. Rio de Janeiro, 1997, 212 p.

EMPRESA BRASILEIRA DE PESQUISA AGROPECUÁRIA (EMBRAPA). Sistema brasileiro de classificação de solos. 2. ed. Rio de Janeiro: EMBRAPA Solos, 2006. 306 p.

EPSTEIN, E.; BLOON, J. Nutrição mineral de plantas. 2. ed. Londrina: Planta, 2006. 401 p.

FERREIRA, P. V. Estatística experimental aplicado à agronomia. 3. ed. Maceió: UFAL, 2000. 604 p.
INSTITUTO BRASILEIRO DE GEOGRAFIA E ESTATÍSTICA (IBGE). Sistema IBGE de Recuperação Automática (SIDRA): agricultura. Brasília, 2008. Disponível em: <http://www.sidra.ibge.gov.br/bda/agric $>$. Acesso em: 12 jun. 2008.

LAGREID, M.; BOCKMAN, O. C.; KAARSTAD, O. Agriculture, fertilizers and the environment. Cambridge: CABI. 1999, 294 p.

LIMA, A. A. Maracujá: produção: aspectos técnicos. Brasília: Embrapa Informação Tecnológica, 2002, 104 p. (Frutas do Brasil, 15).

MELLEK, J. E. et al. Dairy liquid manure and no-tillage: Physical and hydraulic properties and carbon stocks in a Cambisol of Southern Brazil. Soil \& Tillage Research, v. 110, n. 01 , p. 69-76, 2010

MUNNS, R.; TESTER, M. Mechanisms of Salinity Tolerance. Annual Review Plant Biology. v. 59, p. 651-681, 2008.

NATALE, W. et al. Adubação nitrogenada e potássica no estado nutricional de mudas de maracujazeiro-amarelo. Acta Scientarium Agronomy, v. 28, n. 02, p. 187-192, 2006.

PRATES, H. S.; MEDEIROS, M. B. de. “MB - 4": entomopatógenos e biofetilizantes na citricultura orgânica. Campinas: Secretaria de Agricultura e Abastecimento, 2001. Folder.

REBELLO, B. M. et al. Effect of a peel passion fruit flour (Passiflora edulis $f$. flavicarpa) extract on the labeling of blood constituents with technetium-99m and on the morphology of red blood cells. Brazilian Archives of Biology and Technology, v. 50 , p. 153-159, 2007. Special number.

RODOLFO JÚNIOR, F.; CAVALCANTE, L. F.; BURITI, E. S. Crescimento e produção do maracujazeiro amarelo em solo com biofertilizantes e adubação mineral com NPK. Caatinga, v. 21, n. 05, p. 134-145, 2008. Número especial.

RODRIGUES, A. C. et al. Produção e nutrição mineral do maracujazeiro amarelo em solo com biofertilizante supermagro e potássio. Revista Brasileira de Engenharia Agrícola e Ambiental, v. 13, n. 02, p. 117-124, 2009.

SANTOS, F. A. et al. A influencia da água e do nitrogênio na cultura do maracujá (Passiflora edulis). Revista Científica Eletrônica de Agronomia, v. 05, n. 10, p. 8-13, 2006.

SANTOS, G. D. Avaliação do maracujazeiro - amarelo sob biofertilizantes aplicados ao solo na forma líquida. 2004. 74 f. Dissertação (Mestrado em Manejo de Solo e da Água) - Centro de Ciências Agrárias, Universidade Federal da Paraíba, Areia, PB, 2004

SOUSA, V. F. de S. et al. Produtividade do maracujazeiro amarelo sob diferentes níveis de irrigação e doses de potássio via fertirrigação. Pesquisa Agropecuária Brasileira, v. 38, n. 04, p. 497-504, 2003.

SOUZA, H. A. et al. Adubação nitrogenada e substratos na produção de mudas de maracujazeiro doce. Ciência e Agrotecnologia, v. 31, n. 03, p. 599-604, 2007. 